\title{
DUAS NOVAS ESPÉCIES SUL-BRASILEIRAS DE BACCHARIS L. (ASTERACEAE-ASTEREAE) $^{1}$ \\ ANABELA SILVEIRA DE OLIVEIRA² LEONARDO PAZ DEBLE ${ }^{3}$
}

\section{RESUMO}

Duas novas espécies de Baccharis L. são descritas e ilustradas: B. albolanosa An. S. de Oliveira \& Deble e B. longoattenuata An. S. de Oliveira.

Palavras-chave: Baccharis, novas espécies, Asteraceae, Astereae.

\section{ABSTRACT}

Two new species of Baccharis L. are here described and illustrated: B. albolanosa An. S. de Oliveira \& Deble and B. longoattenuata An. S. de Oliveira.

Key Words: Baccharis, new species, Asteraceae, Astereae.

\section{INTRODUÇÃO}

São descritas duas novas espécies: Baccharis albolanosa, que habita campos arenosos no sudoeste do estado do Rio Grande do Sul, e Baccharis longoattenuata, de distribuição geográfica mais ampla, ocorrendo na serra do sudeste do Rio Grande do Sul e no litoral sul-brasileiro.

\section{DESCRIÇÃO}

1. Baccharis albolanosa An. S. de Oliveira \& Deble, sp. nov.

TIPO: Brasil, Rio Grande do Sul, São Francisco de Assis, RS 241, para Manoel Viana, em solo arenoso, L. P. Deble \& A. S. de Oliveira 5.109, II.2006. Holotypus MBM. Isotypi CTES, PACA, SI.

Suffrutex erectus, ramosus, dense albo-lanosus, usque ad apice foliosus, $50-120 \mathrm{~cm}$ altus. Folia linearia ad linearoblonga, 5-15 mm longa, 1-2 mm lata, alterna (internodiis usque $5 \mathrm{~mm}$ longis), sessilia, uninervia, concolora vel discolora, supra albo-lanosa ad lanuginosa subtus dense albo-lanosa, integra, revoluta, apice acuta, basi trunculata. Capitula in panicula-racemosa disposita. Involucrum femineum oblongo 7-8-florum, 5-7 $\mathrm{mm}$ altum, 4-5 $\mathrm{mm}$ crassum. Bracteis involucri 4-5-seriatis, dense albo-lanosis, obtusis; externis ovatis vel ovato-orbiculatis, $2-3 \mathrm{~mm}$ longis, 1,7-1,9 mm latis; mediis et intimis oblongis, margine hyalinis, 3,5-5 mm longis, 1,2-1,5 mm latis. Flores feminei corolla tubulosa, 4-4,5 mm longa, apice dentata; stylo 5 mm longo. Pappus sordescens, 4-5 mm longus. Achaenia oblonga, 5-costata, $1,5 \mathrm{~mm}$ longa, puberula, cum pilis geminis et papillis vestita. Involucrum mascularum hemisphaericum, 20-22-florum, 3-4 mm altum et crassum. Bracteis involucri 3-seriatis, dense albo-lanosis, acutis vel obtusis; externis ovato-lanceolatis ad triangulatis, $1-2 \mathrm{~mm}$ longis, $1 \mathrm{~mm}$ latis; intimis oblanceolatis vel oblongis, 2-3 mm longis, 0,8-1 mm latis. Flores mascula corolla tubulosa 2-2,5 mm longa, apice 5-lobata, lobulis $1 \mathrm{~mm}$ longis cum pilis geminis et papillis vestita. Pappus sordescens, 2-2,5 mm longus.

A Baccharis ochracea Spreng., cui maxima proxima, bracteis involucri albo-lanosis (versus luteis vel ferrugineotomentosis), capitula feminei $5-7 \mathrm{~mm}$ altum, $4-5 \mathrm{~mm}$ crassum, cum bracteis 4-5-seriatis (versus 3-4 mm altum, $3 \mathrm{~mm}$ crassum, cum bracteis 2-3-seriatis), differt.

Sufrútice ereto, ramoso, densamente albo-lanoso, folhoso até o ápice, de $50-120 \mathrm{~cm}$ de altura (Figura 1a). Folhas lineares a linear-oblongas (5$15 \mathrm{~mm}$ de comprimento por 1-2 mm de largura), alternas (entrenós de até $5 \mathrm{~mm}$ ), sésseis, uninérvias, concolores a discolores, albo-lanosas a lanuginosas na face adaxial e densamente albo-lanosas na abaxial, agudas no ápice e truncadas na base, de margens íntegras e revolutas

Artigo recebido em 22/08/2006 e aceito para publicação em 10/10/2006.

2 Bióloga, MSc., bolsista CAPES, doutoranda do Programa de Pós-Graduação em Engenharia Florestal, Centro de Ciências Rurais, Universidade Federal de Santa Maria, CEP 97105-900, Santa Maria (RS).anabela.biol@mail.ufsm.br

3 Biólogo, MSc., bolsista CAPES, doutorando do Programa de Pós-Graduação em Engenharia Florestal, Centro de Ciências Rurais, Universidade Federal de Santa Maria, CEP 97105-900, Santa Maria (RS).deble.biol@ gmail.com 
(Figura 1a'). Capítulos pedunculados, ordenados em racemos formando amplas panículas terminais. Invólucro feminino oblongo, de 5-7 mm de altura por 4-5 mm de diâmetro (Figura 1b). Brácteas involucrais densamente albo-lanosas, de ápice obtuso, dispostas em 4-5-séries; as externas, ovadas ou ovado-orbiculares $(2-3 \mathrm{~mm}$ de comprimento por 1,7-1,9 $\mathrm{mm}$ de largura); as medianas e internas, oblongas $(3,5-5 \mathrm{~mm}$ de comprimento por 1,2-1,5 mm de largura), de margens estramíneas e transparentes (Figura 1b'). Flores femininas, 7-8, com corola tubulosa (4-4,5 mm de comprimento) de base engrossada e bordo irregularmente denteado (Figura 1c). Estigma de $5 \mathrm{~mm}$ de comprimento, breve exserto ao tubo da corola; ramas lanceoladas, de $1 \mathrm{~mm}$. Pápus amarelo, com 70-100 cerdas de 4-5 mm de comprimento. Aquênios oblongos, de 1,5 mm de comprimento, 5-costados, pubérulos, com pubescência constituída de pêlos geminados e papilas (Figura 1f). Invólucro masculino hemisférico (3-4 mm de altura e diâmetro). Brácteas involucrais densamente albo-lanosas, agudas ou obtusas no ápice, dispostas em 3-séries; as externas, ovado-lanceoladas a triangulares (1-2 mm de comprimento por $1 \mathrm{~mm}$ de largura); as internas, oblanceoladas ou oblongas, de $2-3 \mathrm{~mm}$ de comprimento por $0,8-1 \mathrm{~mm}$ de largura (Figura 1d). Flores masculinas, 20-22, com corola tubulosa de $2-2,5 \mathrm{~mm}$ de comprimento e ápice 5-lobado, revoluto, com lóbulos de $1 \mathrm{~mm}$, providos de pêlos geminados e papilas (Figura 1e). Rudimento do estigma de 2-2,5 mm de comprimento, com ramos curtos e aderidos entre si. Pápus amarelo, com cerdas de 2-2,5 de comprimento.

Comentários: Baccharis albolanosa pertence à seção Paniculatae Heering emend. Cuatrec., sendo afim a $B$. ochracea Spreng., da qual difere pela pubescência albo-lanosa nas brácteas involucrais (versus lúteo ou ferrugíneo-tomentosa), bem como pelos capítulos femininos com 5-7 $\mathrm{mm}$ de altura e 4-5 $\mathrm{mm}$ de diâmetro (versus 3-4 $\mathrm{mm}$ de altura e $3 \mathrm{~mm}$ de diâmetro), apre- sentando brácteas involucrais dispostas em 4-5séries (versus 2-3-séries). Baccharis albolanosa igualmente demonstra relação $\operatorname{com} B$. artemisioides Hook. \& Arn.; esta espécie, todavia, apresenta pubescência argênteo-tomentosa, invólucro feminino com brácteas dispostas em 3-séries, com dorso apenas pubérulo e pápus de 6-7 mm, exserto 3-4 mm do invólucro (versus $1,5-2 \mathrm{~mm})$.

Distribuição \& Habitat: Baccharis albolanosa habita campos arenosos no sudoeste do Rio Grande do Sul, tendo sido coletada, até o momento, apenas nos municípios de São Francisco de Assis e Manoel Viana. Floresce e frutifica no verão-outono.

Etimologia: Alusão à densa pubescência albolanosa.

Material examinado: BRASIL - RIO GRANDE DO SUL, São Francisco de Assis, zona de campos pedregosos entremeados com matas de galeria, arbusto de $1 \mathrm{~m}$, em afloramento rochoso nos arredores da cidade, capítulos brancos, masculinos, M. Sobral \& D. Falkenberg 6316, II.1990 (ICN 90.340).

2. Baccharis longoattenuata An. S. de Oliveira, sp. nov.

TIPO: Brasil, Rio Grande do Sul, Caçapava do Sul, Guaritas, árvore, cerca de 10-12 metros de altura, na mata, An. S. de Oliveira \& L. P. Deble 1.588, 23.XII.2003. Holotypus MBM. Isotypi CTES, SI.

Arbor vel frutex ramosus, 4-15 $m$ altus. Folia obovata, 2,5-4 cm longa, 1-1,5 cm lata, alterna (internodiis 10-15 mm longis), peninervia, utrinque obtuso-dentata, lanuginosa ad glabra, apice obtusa ad rotunda, basi longo-attenuata. Capitula in corymbis terminalibus. Involucrum femineum oblongo-campanulatum, 6-7 mm altum, 4-5 mm crassum, 20-25-florum. Bracteis involucri 5-seriatis, acutis, margine hyalina; externis ovatolanceolatis, 1,5-2,5 mm longis, 1-1,2 mm latis; mediis oblanceolatis, 3-4 mm longis, $1 \mathrm{~mm}$ latis; internis linearlanceolatis, 5-6 mm longis, 0,5-1 mm latis. Flores feminei corolla tubuloso-filiformia, 4-5 $\mathrm{mm}$ longa, apice dentata. Stylo 5,5 mm longo. Pappus albus, 7-8 mm longus. Achaenia glabra, $2 \mathrm{~mm}$ longa, 10-costata. Involucrum mascularum campanulatum, 5-6 $\mathrm{mm}$ altum, $5 \mathrm{~mm}$ crassum, 20-25florum. Bracteis involucri 5 -seriatis, acutis; externis ovato- 


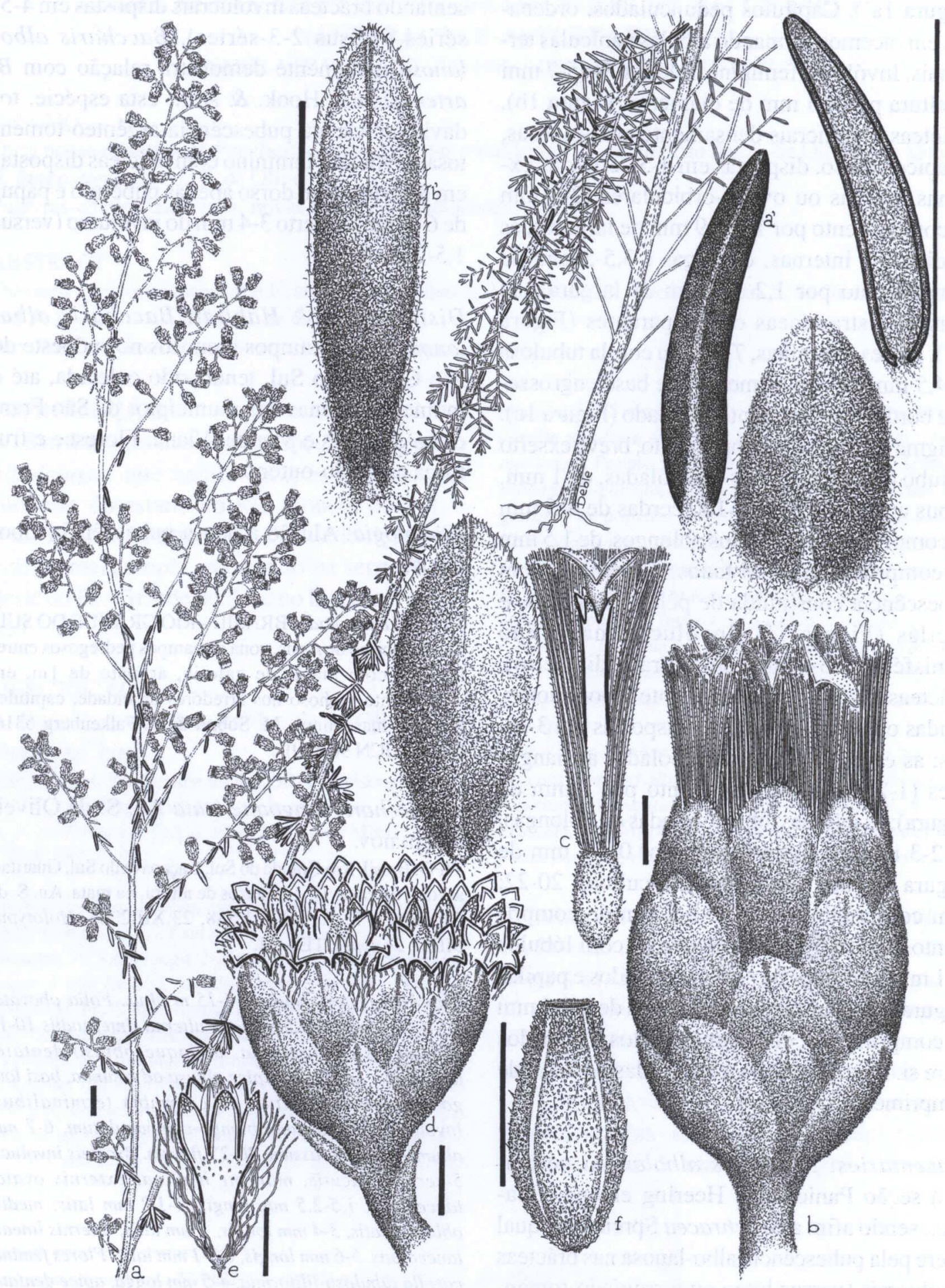

FIGURA 1 - Ramo de exemplar feminino de Baccharis albolanosa An. S. de Oliveira \& Deble (a). Detalhe da folha (a'). Capítulo feminino (b). Brácteas involucrais do capítulo feminino (b'). Flor feminina (c). Capítulo masculino (d). Flor masculina (e). Aquênio (f). (L. P. Deble \& An. S. de Oliveira, 5.109). (a, a' =1 cm; b, c, d, e, f = $1 \mathrm{~mm}$ ) 
lanceolatis, 1-2 mm longis, 1-1,2 mm latis; mediis oblongis, 3-4 mm longis, 1-1,2 mm latis; intimis oblanceolatis, 4-5 mm longis, 0,9-1 mm latis. Flores mascula corolla tubulosa, 5-6 mm longa, apice 5-lobata, lobis 1,5 mm longis, revolutis. Pappus albus, 4-4,5 mm longus. A Baccharis muelleri Baker, cui affinis, foliis obovatis, apice obtusis ad rotundatis, basi longo-attenuatis (versus foliis ellipticis vel lanceolatis, apice acutis, basi attenuatis), involucrum femineum 20-25-florum (versus involucrum femineum 50 60-florum), differt.

Árvore ou arbusto de 4-15 m de altura, ramoso, folhoso até o ápice e normalmente desprovido de folhas na base (Figura 2a). Folhas obovadas (2,5-4 cm de comprimento por 1-1,5 cm de largura), alternas (entrenós de 10-15 mm), peninérvias, denteadas na metade superior, de ápice obtuso a rotundo e base longo-atenuada em pseudopecíolo; lâmina lanuginosa a glabra, composta por tricomas aglomerados, caducos (Figura 2a'). Capítulos agrupados em corimbos no ápice dos ramos. Invólucro feminino de 6-7 $\mathrm{mm}$ de altura por 4-5 mm de diâmetro. Brácteas involucrais 5-seriadas, agudas e enegrecidas no ápice, hialinas na margem; as externas, ovadolanceoladas (1,5-2,5 mm de comprimento por 1$1,2 \mathrm{~mm}$ de largura); as medianas, oblanceoladas (3-4 mm de comprimento por $1 \mathrm{~mm}$ de largura); as internas, linear-lanceoladas, de 5-6 mm de comprimento por $0,5-1 \mathrm{~mm}$ de largura (Figura $2 b$ ). Flores femininas, 20-25, com corola tubuloso-filiforme, de 4-5 mm de comprimento, irregularmente denteada no ápice (Figura 2c). Estigma exserto ao tubo da corola, bífido, de 5,5 $\mathrm{mm}$ de comprimento (Figura 2g). Pápus branco, com cerdas de 7-8 mm de comprimento. Aquênios de $2 \mathrm{~mm}$ de comprimento, 10-costados (Figura 1f). Invólucro masculino campanulado, de 5-6 mm de comprimento por 5 $\mathrm{mm}$ de diâmetro. Brácteas involucrais agudas no ápice, dispostas em 5- séries; as externas, ovado-lanceoladas (1-2 mm de comprimento por 1-1,2 mm de largura); as medianas, oblongas (3$4 \mathrm{~mm}$ de comprimento por 1-1,2 mm de largura); as internas, oblanceoladas, de $4-5 \mathrm{~mm}$ de comprimento por 0,9-1 mm de largura (Figura 2d). Flores masculinas, 20-25, com corola de 5$6 \mathrm{~mm}$ de comprimento e ápice 5-lobado de 1,5 $\mathrm{mm}$, revoluto (Figura 2e). Rudimento do estigma de $6 \mathrm{~mm}$ de comprimento, com ramos curtos e aderidos entre si. Pápus branco de 4-4,5 $\mathrm{mm}$ de comprimento, com cerdas espessadas no ápice.

Comentários: Baccharis longoattenuata demonstra relação com B. muelleri Baker, da qual difere pelas folhas obovadas, obtusas a rotundas no ápice (versus elípticas ou lanceoladas, agudas no ápice), de base longo-atenuada (versus atenuada), bem como pelos capítulos femininos com 20-25 flores (versus 50-60 flores). A nova espécie também se aproxima de B. papillosa, da qual difere pela forma das folhas e capitulescência.

Distribuição \& Habitat: Baccharis longoattenuata ocorre em solos arenosos, na orla de florestas subtropicais, no leste e nordeste do Rio Grande do Sul e sudeste de Santa Catarina. Floresce e frutifica do final da primavera até o verão.

Etimologia: Do latim longus (= comprido) e attenuatus (= fino, reduzido), uma alusão às folhas, que apresentam base longamente atenuada em pseudopecíolo.

Observação: Baccharis longoattenuata é freqüentemente determinado como $B$. mesoneura DC. ou B. lateralis Baker. A primeira espécie apresenta hábito subarbustivo, folhas trinervadas, capitulescência em panículas terminais, bem como capítulos femininos de 3-4 mm de altura. B. lateralis é um subarbusto, com capítulos na axila das folhas superiores, sendo os femininos cilíndricos, de pápus não acrescente e apenas 2-4 flores. As estampas 206 e 216 (sob os nomes de Baccharis mesoneura e $B$. pseudomyriocephala, respectivamente) constantes em Barroso \& Bueno (2002), correspondem a exemplares de $B$. longoattenuata. 


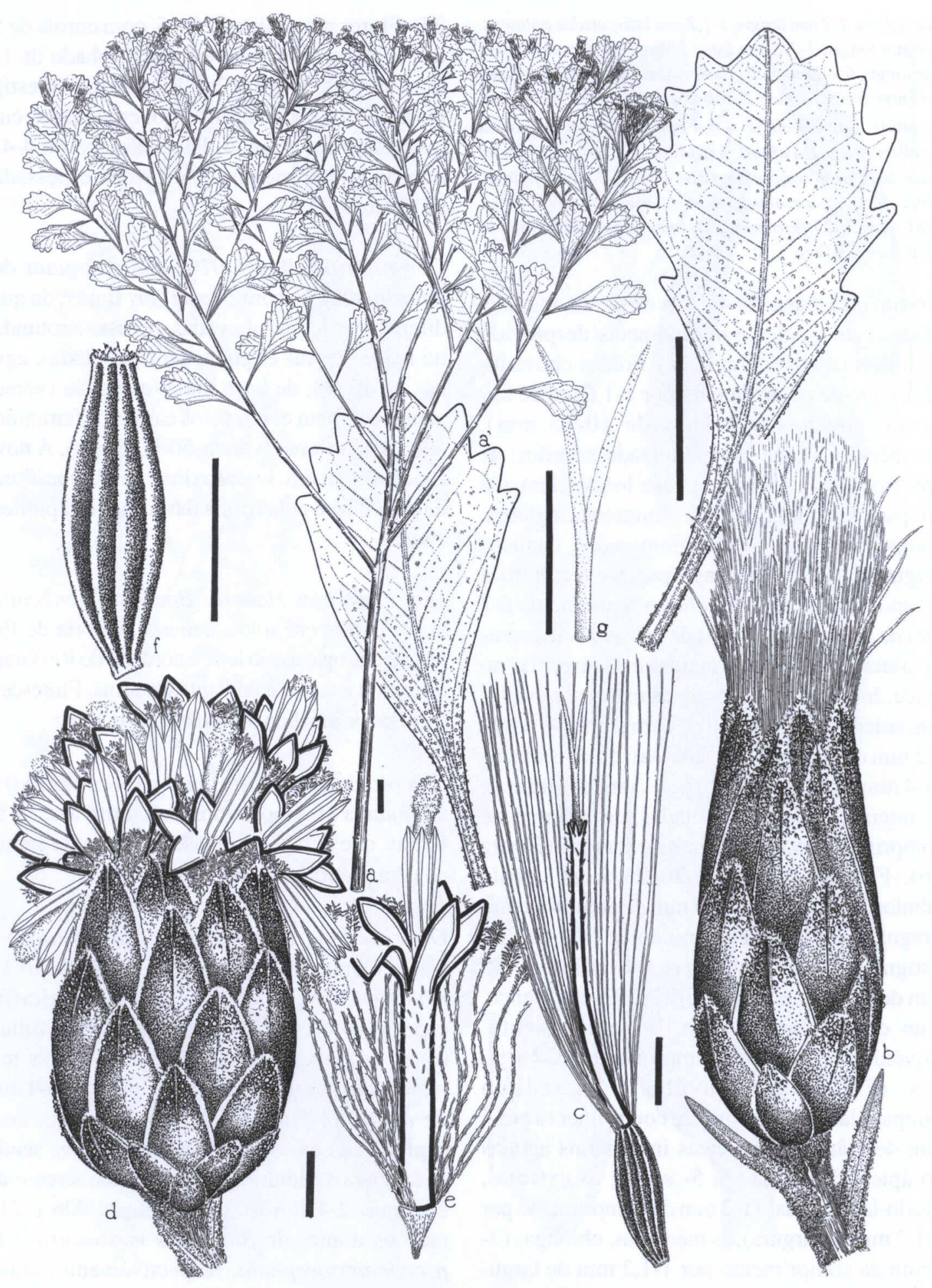

FIGURA 2 - Ramo de exemplar feminino de Baccharis longoattenuata An. S. de Oliveira (a). Folhas (a'). Capítulo feminino (b). Flor feminina (c). Capítulo masculino (d). Flor masculina (e). Aquênio (f). Detalhe do estigma (g). (An. S. de Oliveira \& L. P. Deble, 1.588 ). (a, a'=1 cm; b, c, d, e, $\mathrm{f}=1 \mathrm{~mm})$ 
Material examinado: BRASIL - RIO GRANDE DO SUL, Arroio do Sal, balneário Rondinha Velha, arvoreta com mais ou menos $4 \mathrm{~m}$ de altura em beira de mata, solo arenoso, M. G. Rossoni 43, 21.IV.1990 (RB 343.616). Morro Grande, p. Osório, in silvula arenosa, B. Rambo, 10.I.1952 (PACA 51.781). Palmares do Sul, Lagoa da Porteira, em borda de mata de restinga, J. Mauhs, 18.XII.2002 (PACA 87.069). Torres, região de mata atlântica (mata ombrófila densa), arbusto de 1,5-2 m, em beira de estrada, capítulos creme, flores masculinas, M. Sobral et al. 8.932, III.2000 (ICN 123.086). SANTA CATARINA, Florianópolis, Canasvieiras, campo úmido, R. M. Klein, R. Souza \& A. Bresolin 5.909, 6.X.1964 (HBR) Garopaba, Siriú, dunas, A. Bresolin \& R. S. Sobrinho 61, 19.XII.1970 (HBR). Sombrio, Araranguá, árvore no campo, flor branca, R. Reitz 1.805, 30.XII.1945 (ICN 19.565).

\section{BIBLIOGRAFIA}

Baker, J. Compositae III. Asteroidae. In: Martius. Flora Brasiliensis. München, Wien, Leipzig, 1882. v. 6, parte III, p. 1-132.

Barroso, G. M. Compositae - Subtribo Baccharidinae Hoffmann. Estudo das espécies ocorrentes no Brasil. Rodriguésia, Rio de Janeiro, v. 28, n. 40, 1976, 273p.

Barroso, G. M., Bueno, O. L. Compostas, 5. Subtribo: Baccharidinae. Flora Ilustrada Catarinense, Itajaí, p. 765-1065. 2002.
Cuatrecasas, J. Revisión de las especies colombianas del género Baccharis. Revista Academia Colombiana Ciencias Exatas, Bogotá, n. 13, p. 5-102. 1967.

De Candolle, A. P., Prodr. Syst. Nat. Reg. Veget., Paris, 6, p. 398-429, 1838.

Giuliano, D. Subtribu Baccharinae: Baccharis. In: A. T. Hunziker (ed.). Flora fanerogámica argentina, Córdoba, v. 66, p. 1-73, 2000.

Giuliano, D. Clasificación infragenérica de las especies argentinas de Baccharis (Asteraceae, Astereae). Darwiniana, San Isidro, v. 39, p.131-154, 2001.

Giuliano, D. New infragenera in Baccharis (Asteraceae, Astereae). Novon, San Francisco, v. 15, n. 4, p. 535$541,2005$.

Hellwig, F. Taxonomy and evolution of Baccharidinae (Compositae). In: D. J. N. Hind \& H. J. Beentje (ed.), Compositae: Systematics. Proceedings of the International Compositae Conference, Kew, v. 1, p. $575-590,1996$.

Malagarriga Heras, R. de P. Nomenclator Baccharidinarum Omnium. Mem. Soc. Cien. Nat. La Salle, Caracas, 37, n. 107, 1977.

Müller, J. Systematics of Baccharis (Compositae-Astereae) in Bolivia, including an overview of the genus. Systematics Botany Monographs, v. 76, p. 1-339, 2006.

Oliveira, A. S., Deble, L. P., Schneider, A. A., Marchiori, J. N. C. Checklist do gênero Baccharis L. (AsteraceaeAstereae) para o Brasil. Balduinia, Santa Maria, n. 9, p. 17-27, 2006. 